\title{
Breastfeeding Practices among Mothers in Southwest Nigeria
}

\author{
Adebayo Akadri ${ }^{1 *}$, Oluwaseyi Odelola ${ }^{2}$
}

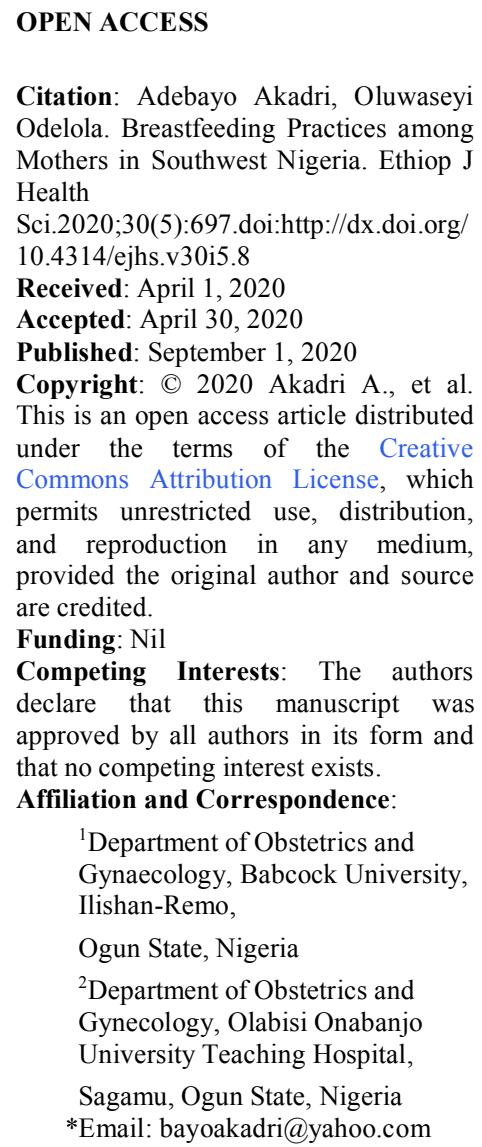

\begin{abstract}
BACKGROUND: This study was conducted to determine the breastfeeding practices among parous antenatal attendees in two teaching hospitals in Southwest Nigeria.

METHODS: A cross-sectional study was carried out on 340 parous antenatal clinic attendees in two teaching hospitals in Ogun State, Nigeria. A structured questionnaire was used to obtain data on breastfeeding practices. Data were analyzed using Statistical Package for Social Sciences (SPSS) windows version 21.0 (IBM Corp., Armonk, NY, USA).

RESULTS: Out of a total of 340 women, 319 (93.8\%) breastfed their last babies. The median duration of breastfeeding was 15 months. One hundred and thirty two women (38.8\%) initiated breastfeeding within 30 minutes of delivery, and 200 women (58.8\%) exclusively breastfed their babies for six months. The majority of the women, $299(87.9 \% \mathrm{k})$ did not report any problem associated with breastfeeding. Logistic regression analysis showed that women who had no breastfeeding problems were more likely to exclusively breastfeed their infants for six months compared to those with breastfeeding problems (AOR 3.4; CI 1.6-7.1; $P=0.001)$. Similarly, women who got breastfeeding information from mass media were more likely to practice exclusive breastfeeding for six months compared to those that got breastfeeding information from other sources (AOR42.2; CI 3.1568.5; $P=0.005$ ).

CONCLUSION: Exclusive breastfeeding is suboptimal in Ogun State, Nigeria. Provision of breastfeeding information via mass media will assist in improving breastfeeding practice. Educating mothers on the techniques that help to prevent breastfeeding complications will also be beneficial.

KEYWORDS: Breast milk, Breastfeeding, exclusive breastfeeding, Nigeria, Practices

\section{INTRODUCTION}

Adequate nutrition is essential for optimal growth and development of infants. Breast milk is natural and contains all the necessary nutrients required by infants in the first six months of life (1). In addition to being an important source of energy and nutrients, breast milk also has immunological properties and thus lowers the chance of infants becoming ill or dying from infections such as
\end{abstract}


gastroenteritis, pneumonia and meningitis $(2,3)$. It has been estimated that optimal breastfeeding could reduce under-five mortality worldwide by as much as 823,000 each year (4). The beneficial effects of breastfeeding extends beyond infancy. Evidence suggests that breastfeeding protects against childhood obesity, and adolescents who were breastfed as babies were likely to be more intelligent than those who were not breastfed (3). Research has also shown that breastfeeding is possibly protective against chronic noncommunicable diseases such diabetes and hypertension (5).

The World Health Organization (WHO) and the United Nations Children's Fund (UNICEF) have identified breastfeeding as the single most effective and affordable feeding practice necessary for development of healthy infants (6). These organizations have thus recommended initiation of breastfeeding within one hour of birth, exclusive breast feeding for the first six months of life and continued breastfeeding up to two years of age or beyond (3).

Exclusive breastfeeding is when only breast milk is given to the child, except for medicines, vitamins or mineral supplements (7). There appears to be universal awareness about exclusive breastfeeding among women in many countries; however, breastfeeding practices are often not aligned with recommendations $(8,9)$. Globally, only $43 \%$ of newborns have breastfeeding initiated within one hour of birth, and $40 \%$ of infants aged six months or less are exclusively breastfed (3). In sub-Saharan Africa, studies have shown that the prevalence of early initiation of breastfeeding ranges from $37.8 \%$ to $69.3 \%$ while the prevalence of exclusive breastfeeding ranges from $23.7 \%$ to $56.5 \%$ (10). A recent national survey suggested that only $29 \%$ of infants less than six months were exclusively breastfed in Nigeria (11). There is no data on the average duration of exclusive breastfeeding in south west Nigeria; however, over $70 \%$ of women in southwest Nigeria breastfeed their infants for up to a year (9).

Breastfeeding practices may be influenced by several factors such as psychosocial, cultural, economic and health factors (9). In a study done in Ghana, the educational status, age and ethnicity of women were found to be strong predictors of maternal practice of exclusive breastfeeding (12). Access to breastfeeding counseling during pregnancy, vaginal mode of delivery and support by husband are also factors that positively influence the initiation and maintenance of breastfeeding $(2,13,14)$. The occupation and work schedule of nursing mothers often times act as barriers to optimal breastfeeding $(15,16)$. Women who resume work before their babies are six months old will likely find it difficult to adhere to the recommendation of exclusive breastfeeding (15). The provision of nursing areas in the work environment may assist nursing mothers in improving breastfeeding practices. Support to breastfeeding mothers in the form of job flexibility and rearrangement of work schedule may also enable them to breastfeed successfully $(15,16)$.

Optimal breastfeeding practices are linked to achieving global goals. The second sustainable development goal (SDG) focuses on improving nutrition and ending hunger while the third SDG aims at ensuring healthy lives and promoting the well-being of individuals of all ages (6). It is clear that the promotion of breastfeeding in all countries will be an important strategy in achieving these goals among infants and young children (6).

Breastfeeding practices are often culture dependent; hence, a proper understanding of the factors that influence them in any particular cultural setting is important in designing successful interventions. This study is aimed at determining the breastfeeding practices among parous antenatal attendees in two tertiary hospitals in Southwest Nigeria.

\section{MATERIALS AND METHODS}

Study setting and design: This cross-sectional study was carried out at the antenatal clinics of Babcock University Teaching Hospital (BUTH), and Olabisi Onabanjo University Teaching Hospital (OOUTH). Both hospitals are in Ogun State, Nigeria. The target population included all pregnant women attending antenatal clinic at the hospitals who had practiced breastfeeding in previous pregnancy. 
Sample size and sampling technique: The minimum sample size for the study was determined using the Leslie-Kish formula (17): $\left(\mathrm{n}=\mathrm{Z}^{2} \mathrm{pq} / \mathrm{d}^{2}\right)$, where $\mathrm{n}$ is the desired sample size; $\mathrm{Z}$ is the standard normal deviate set at 1.96 (for $95 \%$ confidence interval); $\mathrm{p}$ is the prevalence of exclusive breastfeeding in the target population; $q=1-p$ and $d$ is the degree of accuracy desired, set at 0.05 . An extrapolation from the Nigerian demographic and health survey (11) suggests a prevalence of breast feeding of $27.8 \%$; hence, the calculated sample size was 308 . By considering a $10 \%$ attrition rate, the overall minimum sample size was 339 . Three hundred and forty eligible pregnant women were recruited for the study. These women were recruited consecutively from each study center until the estimated sample size was obtained.

Data collection: A structured questionnaire was used to obtain information on the sociodemographic characteristics of each study participant such as the age, parity, religion and level of education. The women were also asked about the place where they had antenatal care (ANC) in the last pregnancy and where they had their last delivery (hospital, mission centre, traditional birth attendants (TBA), home). Information on the initiation, duration and pattern of breastfeeding following the last delivery was also recorded. Breastfeeding practices were assessed by asking the women the time interval between delivery and initiation of breastfeeding, the duration of exclusive breastfeeding, and the total duration of breastfeeding. The problems encountered by the women during breastfeeding were assessed by asking questions regarding the presence or absence of cracked nipples and breast engorgement. Women who reported poor milk production during breastfeeding were said to have inadequate lactation. The sources of information regarding breastfeeding (health workers, mass media, family) were also recorded on the questionnaire.

Statistical analysis: Data were analyzed using Statistical Package for Social Sciences (SPSS) windows version 21.0 (IBM Corp., Armonk, NY, USA). Continuous variables were summarized using descriptive statistics. The age of study respondents was summarized using mean and standard deviation at 95\% confidence interval. The parity, duration of exclusive breastfeeding and total duration of breastfeeding of the study respondents were summarized using median and interquartile range. Categorical variables were summarized using frequencies and percentages. Pearson's Chi-square test was used to establish the association between some respondents' factors and practice of exclusive breastfeeding. All the significantly associated variables were entered into a multivariate logistic regression model to determine probable determinants of the practice of exclusive breastfeeding. The reference variables were 'TBA' for site of antenatal care in last pregnancy; 'home' for place of last delivery; 'family' for source of breastfeeding information; and 'yes' for lactational problems. The model explained $16.0 \%$ (Nagelkerke R2) of the variance in exclusive breastfeeding and correctly classified $65.9 \%$ of cases. Statistical significance was set at $P$ value less than 0.05 .

Ethical considerations: Ethical approval for the study was obtained from the Babcock University Health Research Ethics Committee (BUHREC). The research was conducted in accordance with the World Medical Association Declaration of Helsinki. The study participants were given adequate information on the study, and those who agreed to participate in the study signed a written consent form. The study participants were assured of the confidentiality of data obtained from them. The data set was anonymised to ensure privacy.

\section{RESULTS}

Three hundred and forty women participated in the study. The mean age (SD) of the study participants was 32.9(4.8) years. The majority, $220(64.7 \%)$ were within the 30-39 age range, and $241(70.9 \%)$ had a parity $\leq 2$. The median parity was 2 with interquartile range of 1-3. Two hundred and seventy two study participants $(80 \%)$ were Christians, and the majority, 172 $(50.6 \%)$ had tertiary level education (Table 1$)$. 
Table 1: Socio-demographic characteristics ( $\mathbf{N}$ =340).

\begin{tabular}{ll}
\hline $\begin{array}{l}\text { Sociodemographic } \\
\text { characteristics }\end{array}$ & $\begin{array}{l}\text { Frequency } \\
(\%)\end{array}$ \\
\hline Age & \\
$20-29$ & $94(27.6)$ \\
$30-39$ & $220(64.7)$ \\
$\geq 40$ & $26(7.6)$ \\
Parity & \\
$\leq 2$ & $241(70.9)$ \\
$>2$ & $99(29.1)$ \\
Religion & \\
$\quad$ Christianity & $272(80)$ \\
$\quad$ Islam & $68(20)$ \\
Level of Education & \\
$\quad$ Primary & $16(4.7)$ \\
$\quad$ Secondary & $152(44.7)$ \\
Tertiary & $172(50.6)$ \\
\hline
\end{tabular}

A total of 319 women (93.8\%) breastfed their last babies. The median duration of breastfeeding of the study participants was 15 months with interquartile range of $12-18$ months. One hundred and thirty two women $(38.8 \%)$ initiated breastfeeding within one hour of delivery, and 200 women (58.8\%) exclusively breastfed their babies for six months. The median duration of exclusive breastfeeding was 6 months with interquartile range of 3 6 months. The majority of the women, 246 (72.4\%), continued breastfeeding beyond one year. Inadequate lactation was the most common problem associated with breastfeeding, affecting $22(6.5 \%)$ of the women; the majority of the women did not report any problem associated with breastfeeding $299(87.9 \%)$.Two hundred and sixty eight study participants (78.8\%) received information about breastfeeding from health workers, $56(16.5 \%)$ received information from family and friends while $16(4.7 \%)$ received breastfeeding information from mass media (Table 2).

The association between selected predictor variables and the practice of exclusive breastfeeding is depicted in Table 3. The type of health facilities where antenatal clinic and delivery were held in last pregnancy were shown to have statistically significant association with the practice of exclusive breastfeeding for six months $(P=0.001 ; 0.004$ respectively $)$. Similarly, other factors such as the source of information on breastfeeding and the absence of problems with lactation also had statistically significant association with the practice of exclusive breastfeeding for six months $(P=0.003 ; 0.004$ respectively). The age, parity and education of the study participants had no association with the practice of exclusive breastfeeding.

Table 2: Breast feeding practices among study participants

\begin{tabular}{lll}
\hline Breast feeding practices & $\begin{array}{l}\text { Frequency } \\
(\mathrm{n}=340)\end{array}$ & $\mathbf{\%}$ \\
\hline Breastfed their last baby & & \\
$\quad$ Yes & 319 & 93.8 \\
$\quad$ No & 21 & 6.2 \\
Initiation of breastfeeding & & \\
(Hours) & 132 & 38.8 \\
$\quad<1$ & 69 & 20.3 \\
$1-2$ & 41 & 12.0 \\
$2-24$ & 43 & 12.7 \\
$24-48$ & 43 & 12.7 \\
$>48$ & 12 & 3.5 \\
Can't remember & & \\
Duration of exclusive & & \\
breastfeeding (Months) & 72 & 21.2 \\
$<1$ & 12 & 3.5 \\
2 & 13 & 3.8 \\
3 & 17 & 5.0 \\
4 & 26 & 7.7 \\
5 & 200 & 58.8 \\
6 & & \\
Breastfeeding beyond 1 year & 246 & 72.4 \\
Yes & 94 & 27.6 \\
No & & \\
Problems associated with & & \\
breastfeeding & & \\
None & 299 & 87.9 \\
Inadequate lactation & 22 & 6.5 \\
Cracked nipple & 17 & 5.0 \\
Breast engorgement & 2 & 0.6 \\
Sources of breastfeeding & & \\
information & & 78.8 \\
Health workers & 268 \\
$\begin{array}{l}\text { Family and friends } \\
\text { Mass media }\end{array}$ & 56 & 16.5 \\
\hline & 16 & 4.7 \\
\hline
\end{tabular}


Table 3: Association between predictor variables and the practice of exclusive breastfeeding for 6 months.

\begin{tabular}{|c|c|c|c|}
\hline \multirow[t]{2}{*}{ Predictor variables } & \multicolumn{2}{|c|}{ Exclusive breastfeeding } & \multirow[t]{2}{*}{$P$ value } \\
\hline & Yes $(n=200)$ & $\operatorname{No}(n=140)$ & \\
\hline \multicolumn{4}{|l|}{ Age (Years) } \\
\hline $20-29$ & $55(27.5)$ & $39(27.9)$ & \multirow[t]{3}{*}{0.990} \\
\hline $30-39$ & $130(65.0)$ & $90(64.3)$ & \\
\hline$\geq 40$ & $15(7.5)$ & $11(7.8)$ & \\
\hline \multicolumn{4}{|l|}{ Parity } \\
\hline$\leq 2$ & $148(74.0)$ & $93(66.4)$ & \multirow[t]{2}{*}{0.146} \\
\hline$>2$ & $52(26.0)$ & $47(33.6)$ & \\
\hline \multicolumn{4}{|l|}{ Education } \\
\hline Primary & $5(2.5)$ & $11(7.9)$ & \multirow[t]{3}{*}{0.061} \\
\hline Secondary & $89(44.5)$ & $63(45.0)$ & \\
\hline Tertiary & $106(53.0)$ & $66(47.1)$ & \\
\hline \multicolumn{4}{|c|}{ Facility where ANC was held last pregnancy } \\
\hline Hospital & 198(99.0) & $126(90.0)$ & \multirow[t]{3}{*}{$0.001^{*}$} \\
\hline Mission centre & $1(0.5)$ & $4(2.9)$ & \\
\hline TBA & $1(0.5)$ & $10(7.1)$ & \\
\hline \multicolumn{4}{|c|}{ Facility where last delivery was conducted } \\
\hline Hospital & $184(92.0)$ & $115(82.2)$ & \multirow[t]{4}{*}{$0.004^{*}$} \\
\hline Mission centre & $6(3.0)$ & $6(4.3)$ & \\
\hline TBA & $1(0.5)$ & $10(7.1)$ & \\
\hline Home & $9(4.5)$ & $9(6.4)$ & \\
\hline \multicolumn{4}{|c|}{ Source of information on BF } \\
\hline Health worker & $162(81.0)$ & $106(75.7)$ & \multirow[t]{3}{*}{$0.003^{*}$} \\
\hline Family \&friend & $24(12.0)$ & $32(22.9)$ & \\
\hline Mass media & $14(7.0)$ & $2(1.4)$ & \\
\hline \multicolumn{4}{|l|}{ Lactation problems } \\
\hline None & $185(92.5)$ & $114(81.4)$ & \multirow[t]{2}{*}{$0.004^{*}$} \\
\hline Yes & $15(7.5)$ & $26(18.6)$ & \\
\hline
\end{tabular}

The significantly associated variables were entered into a multivariate logistic regression model (Table 4), and analysis showed that women who got breastfeeding information from mass media were more likely to practice exclusive breastfeeding for six months when compared to those that got breastfeeding information from other sources (AOR42.2; CI 3.1-568.5; $P=0.005)$. Similarly, women who had no breastfeeding problems were more likely to exclusively breastfeed their infants for six months compared to those with breastfeeding problems (AOR 3.4; CI 1.6-7.1; $P=0.001$ ). 
Table 4: Logistic regression analysis of predictor variables of exclusive breastfeeding for 6 months

\begin{tabular}{|c|c|c|c|c|c|}
\hline \multirow[t]{2}{*}{ Predictor variables } & \multicolumn{2}{|c|}{ Exclusive breastfeeding } & \multirow[t]{2}{*}{ AOR } & \multirow[t]{2}{*}{ CI } & \multirow[t]{2}{*}{$P$ value } \\
\hline & $\begin{array}{l}\text { YES } \\
(n=200)\end{array}$ & $\begin{array}{l}\text { NO } \\
(n=140)\end{array}$ & & & \\
\hline \multicolumn{6}{|c|}{ ANC site in last pregnancy } \\
\hline Hospital & 198(99.0) & $126(90.0)$ & 14.6 & $0.9-251.7$ & 0.064 \\
\hline Mission centre & $1(0.5)$ & $4(2.9)$ & 4.7 & $0.2-129.2$ & 0.363 \\
\hline TBA & $1(0.5)$ & $10(7.1)$ & 1.0 & & \\
\hline \multicolumn{6}{|c|}{ Place of last delivery } \\
\hline Hospital & $184(92.2)$ & $115(82.2)$ & 0.8 & $0.3-2.4$ & 0.657 \\
\hline Mission centre & $6(3.0)$ & $6(4.3)$ & 0.4 & $0.1-2.1$ & 0.267 \\
\hline TBA & $1(0.5)$ & $10(7.1)$ & 0.2 & $0.01-4.9$ & 0.343 \\
\hline Home & $9(4.5)$ & $9(6.4)$ & 1.0 & & \\
\hline \multicolumn{6}{|c|}{ Source of information on BF } \\
\hline Health workers & $162(81.0)$ & $106(75.7)$ & 1.5 & $0.8-3.0$ & 0.201 \\
\hline Mass media & $14(7.0)$ & $2(1.4)$ & 42.2 & $3.1-568.5$ & $0.005^{*}$ \\
\hline Family & $24(12.0)$ & $32(22.9)$ & 1.0 & & \\
\hline \multicolumn{6}{|l|}{ Lactation problem } \\
\hline None & $185(92.5)$ & $114(81.4)$ & 3.4 & $1.6-7.1$ & $0.001^{*}$ \\
\hline Yes & $15(7.5)$ & $26(18.6)$ & 1.0 & & \\
\hline
\end{tabular}

\section{DISCUSSION}

This study assessed the breastfeeding practices among parous antenatal attendees in two tertiary hospitals in Southwest Nigeria. Findings indicate that more than $90 \%$ of the respondents engaged in breastfeeding and the majority continued breastfeeding for between 12 to 18 months. However, fewer than $40 \%$ of the women initiated breastfeeding within one hour of delivery while fewer than $60 \%$ exclusively breastfed their babies for six months. This could indicate that although breastfeeding is widespread among women in southwest Nigeria, the overall practice does not align adequately with the WHO recommendations.

Optimal breastfeeding is a simple, cost effective way of improving the nutrition and well being of infants and young children. This is particularly important in many low and middle income countries where there appears to be a higher burden of malnutrition and micronutrient deficiencies (8). Breastfeeding is a culturally accepted practice in many ethnic groups in
Nigeria $(9,18,19)$. Studies also indicate a high level of awareness and knowledge about breastfeeding among women in south west Nigeria $(9,15,20,21)$. This may have been responsible for the high proportion of respondents who engaged in some form breastfeeding. Similar findings were reported by other researchers $(22,23)$.

The median duration of breastfeeding was 15 months and this was similar to 15.1 months and 14.6 months reported in Edo state, SouthSouth Nigeria and Abuja, federal capital territory, Nigeriarespectively $(24,25)$. The variations in breastfeeding duration in different regions of Nigeria may reflect some differences in socio-cultural practices (23). Other factors such as occupation and socioeconomic status of women may impact on the duration of breastfeeding (22). Women with highly skilled occupations are likely to have demanding work schedules, thus unable to breastfeed for long periods $(23,26)$.

Only $38.8 \%$ of respondents in this study initiated breastfeeding within the first hour of birth. This is similar to rate of $39.9 \%$ reported 
from a study done in Ghana (27), but lower than $59.2 \%$ and $52.6 \%$ documented by a studies in Lagos and Ethiopia $(2,18)$. Some of the reasons commonly cited for late initiation of breastfeeding include: poor milk production, caesarean delivery, baby's refusal to suck and aversion for colostrum (which is believed to be unclean by some cultures) $(23,28)$. Early initiation of breastfeeding is very important because the initial milk produced (colostrum) is rich in immunoglobulins which protects the newborn until his/her immune system starts to function (2). Early initiation of breastfeeding is also important in nurturing maternal-infant bonding (29). Appropriate education of women and the provision of supportive environment in places of delivery will help address most of the issues relating to late initiation of breastfeeding.

Breastfeeding was continued beyond one year in more than $70 \%$ of the women. This is similar to findings from a previous study (9) done in south western Nigeria which reported that $73 \%$ of currently breastfeeding mothers intended to breastfeed for up to a year. It is however not uncommon for women to have the intention of breastfeeding adequately but not able to do so because of difficulties experienced during the process (9,30). In this study, inadequate lactation was the most frequently identified lactation problem, and this was reported in $6.5 \%$ of the respondents. This is similar to findings from another study in south west Nigeria (9). The economic challenges presently being experienced in Nigeria may also contribute to reduction in duration of breastfeeding since mothers may be forced to return to full time work early. Workplace fatigue and the lack of conducive environment for breastfeeding in many places of work may also contribute to early weaning (31). Provision of work-time breaks and on-site rooms for breastfeeding are important strategies that may enable more women to breastfeed for longer periods (31).

There are numerous benefits of exclusive breastfeeding; evidence suggests however that the practice is suboptimal even in low resource countries like Nigeria (9). The median duration of exclusive breastfeeding was six months. The proportion of women who engaged in exclusive breastfeeding for the recommended six months was however $58.8 \%$. A previous study in Sagamu, south west Nigeria had reported a similar prevalence of exclusive breastfeeding of $56.1 \%$ among mothers of children less than 2 years old (22). Other researchers in south west Nigeria reported exclusive breastfeeding rates ranging from $11 \%$ to $86.2 \%(9,15,32)$. The differences in study settings (urban or rural), the employment status and work demands of the women may be partly responsible for the wide variations in the rates of exclusive breastfeeding $(2,9,20)$.

Several demographic, cultural, psychosocial and maternal health factors have also been reported to have association with the initiation of breastfeeding, duration of breastfeeding and the practice of exclusive breastfeeding $(2,9,12,33)$. In this study maternal age had no association with the practice of exclusive breastfeeding. Similar finding was reported in a previous study done in Sagamu (22).There are conflicting reports on the influence of maternal educational status on breastfeeding practice (12,23,33-35). In this study maternal educational status had no association with the practice of exclusive breastfeeding; similar finding was reported by researchers in Sokoto, north-west Nigeria (28). In Enugu, south-east Nigeria, mothers that attained tertiary level of educational were found to be more likely to breastfeed exclusively when compared with those with lower educational attainment (33). Similar finding was reported by Ogbo et al (34). It is assumed that women with high level of education probably had better knowledge about breastfeeding and this led to better breastfeeding practice (35). However, some other researchers have reported an inverse relationship between maternal educational attainment and breastfeeding practice $(12,23)$. These researchers argued that women with high educational attainment usually engage in formal employments with busy schedules which negatively impacts on their ability to breastfeed $(12,23)$.

The majority of the study respondents had their antenatal care and deliveries in health facilities and such women were significantly more likely to practice of exclusive 
breastfeeding for six months. Similar findings were reported by Agbo et al and this may indicate that appropriate information about breast feeding was being passed to women by health workers during antenatal visits (35). More than three quarters of the study participants received breast feeding information from health workers in health facilities where they had their antenatal care and deliveries. Similar findings were reported by other researchers $(26,33)$. The sources of breastfeeding information had statistically significant association with the practice of exclusive breastfeeding for six months; similar findings were reported by researchers in Enugu, south-east Nigeria (33). Although fewer than $5 \%$ of the study respondents received breastfeeding information through mass media, these women were significantly more likely to practice exclusive breastfeeding for six months. This may indicate that the media may also be a good source of breastfeeding information (33). Reports from some researchers also suggest that receiving breast feeding information via the mass media leads to early initiation of breast feeding (31).

About $12 \%$ of women in this study reported breastfeeding problems such as breast engorgements, cracked nipples and inadequate lactation. These problems may be the consequence of poor breastfeeding positioning and improper latching (36).

In this study, women without any lactation problems were significantly more likely to practice exclusive breast feeding. The integration of routine lactation consultation into early postpartum visits, and adequate counseling on proper techniques of breastfeeding will help to prevent these lactation problems and improve the practice of breastfeeding (37).

This study has some limitations. One is the potential for recall bias because mothers had to remember the details of breastfeeding practices following their last delivery, and the capacity to give correct information may depend on the time interval since last delivery. Also, the fact that the study was conducted in tertiary hospitals meant that results may not be a full reflection of the practice in southwest Nigeria as many women have their deliveries at home, with traditional birth attendants, and in primary and secondary health centers.

In conclusion, exclusive breastfeeding is suboptimal in Ogun State, south west Nigeria. Provision of breastfeeding information via mass media and teaching mothers the techniques that help to prevent breastfeeding complications will assist in improving breastfeeding practice. The prioritization of these interventions to encourage breastfeeding will be useful in the global quest to achieve the sustainable development goals.

\section{REFERENCES}

1. Salami LI. Factors influencing breastfeeding practices in Edo State, Nigeria. Afr J Food Agric Nutr Dev 2006; 6(2): 1-12

2. Elyas L, Mekasha A, Admasie A, Assefa E. Exclusive breastfeeding practices and associated factors among mothers attending private pediatric and child clinics, Addis Ababa, Ethiopia: a cross-sectional study. Int $J$ Pediatr 2017; 2017: 8546192. doi: $10.1155 / 2017 / 8546192$.

3. World Health Organization. Infant and young child feeding. Geneva: World Health Organization; 2018.https://www.who.int/en/newsroom/fact-sheets/detail/infant-and youngchild-feeding. Accessed $6^{\text {th }}$ February 2020.

4. Victora CG, Bahl R, Barros AJD, França GVA, Horton S, Krasevec J, et al. Breastfeeding in the 21st century: epidemiology, mechanisms, and lifelong effect. Lancet. 2016;387:475-90.

5. Kelishadi R, Farajian S. The protective effects of breastfeeding on chronic noncommunicable diseases in adulthood: A review of evidence. Adv Biomed Res. 2014; 3:3.https://doi.org/10.4103/2277-9175. 124629 PMID: 24600594

6. Katsinde SM, Srinivas SC. Breast feeding and the sustainable development agenda. Indian Journal of Pharmacy Practice 2016: 9(3): 144-146

7. Chola L, Fadnes LT, Engebretsen IMS, Nkonki L, Nankabirwa V, Sommerfelt H, et al. Cost-Effectiveness of Peer Counseling for the Promotion of Exclusive Breastfeeding in Uganda 2015. PLoS ONE 
10(11): e0142718. doi:10.1371/journal. pone. 0142718

8. Swigart TM, Bonvecchio A, The'odore FL, Zamudio-Haas S, Villanueva-Borbolla MA, Thrasher JF. Breastfeeding practices, beliefs, and social norms in low-resource communities in Mexico: Insights for how to improve future promotion strategies. PLOS ONE 2017; 12(7): e0180185. https://doi.org/10.1371/journal.pone.018018 5

9. Agunbiade OM, Ogunleye OV. Constraints to exclusive breastfeeding practice among breastfeeding mothers in Southwest Nigeria: implication for scaling up. Int Breastfeed $J$ 2012;7:5. doi. 10. 1186/1746-4358-7-5

10. Issaka AI, Agho KE, Renzaho AMN. Prevalence of key breastfeeding indicators in 29 sub-Saharan African countries: a metaanalysis of demographic and health surveys (2010-2015). BMJ Open. 2017; 7(10): e014145.doi:10.1136/bmjopen-2016-014145

11. National Population Commission (NPC) [Nigeria] and ICF. Nigeria Demographic and Health Survey 2018 Key Indicators Report. Abuja, Nigeria, and Rockville, Maryland, USA: NPC and ICF, 2019.

12. Asare BY, Preko JV, Baafi D, DwumfourAsare B.Breastfeeding practices and determinants of exclusive breastfeeding in a cross-sectional study at a child welfare clinic in Tema Manhean, Ghana. Int Breastfeed $J$ 2018;13:12. doi.org/10.1186/s13006-0180156-y

13. Tewabe T, Mandesh A, Gualu T, Alem G, Mekuria G, Zeleke H. Exclusive breastfeeding practice and associated factors among mothers in Motta town, East Gojjam zone, Amhara Regional State, Ethiopia, 2015: A cross-sectional study. Int Breastfeed $J$ 2017; 12(12). doi. 10. 1186/s 13006-0170103-3

14. Setegn T, Belachew T, Gerbaba M, Deribe $\mathrm{K}$, Deribew A, Biadgilign S. Factors associated with exclusive breastfeeding practices among mothers in Goba district, south east Ethiopia: a cross-sectional study. Int Breastfeed J 2012; 7 (1): 17. doi: 10. 1186/1746-4358-7-17
15. Sadoh AE, Sadoh WE, Oniyelu P. Breast feeding practices among medical women in Nigeria. Niger Med J 2011; 52(1): 7-12

16. Guendelman S, Kosa JL, Pearl M, Graham S, Goodman J, Kharrazi M. Juggling work and breastfeeding: effects of maternity leave and occupational characteristics. Pediatrics. 2009; 123:e38-e46.

17. Kish L. Survey sampling. New York: John Wiley and Sons. 1965 ISBN 047148900x. Available at:http://www..edis.ifas.ufl.edu/pdffiles/PD/ PD00600.pdf [Accessed 18 January 2016]

18. Okafor IP, Olatona FA, Olufemi OA. Breastfeeding practices of mothers of young children in Lagos, Nigeria. Niger J Paed. 2014; 41(1):43-47.

19. Gartner LM, Morton J, Lawrence RA, Naylor AJ, O'Hare D, Schanler RJ, et al. American Academy of Pediatrics Section on Breastfeeding: Breastfeeding and the use of human milk. Pediatrics. 2005, 115: 496-506

20. Balogun MR, Okpalugo OA, Ogunyemi AO, Sekoni AO. Knowledge, attitude, and practice of breastfeeding: A comparative study of mothers in urban and rural communities of Lagos, Southwest Nigeria. Niger Med J 2017;58:123-30

21. Onah S, Osuarah DIC, Ebenebe J, Ezechukwu C, Ekwochi U, Ndukwu I. Infant feeding practices and maternal sociodemographic factors that influence practice of exclusive breastfeeding among mothers in Nnewi south- East Nigeria: a cross-sectional and analytical study. Int Breastfeed $J$. 2014;9:6.

22. Sholeye OO, Abosede OA, Salako AA. Exclusive breastfeeding and its associated factors among mothers in Sagamu, southwest Nigeria. Journal of Health Science 2015, 5(2): 25-31 DOI: 10.5923/j.health.20150502.01

23. Adewuyi EO, Adefemi K. Breastfeeding in Nigeria: a systematic review. Int $J$ Community Med Public Health. 2016;3(2):385-396

24. Atimati AO, Adam VY. Breastfeeding practices among mothers of children aged 124 months in Egor Local Government Area of Edo State, Nigeria. South Afr J Clin Nutr 
2018; 0(0):1-7

https://doi.org/10.1080/16070658.2018.1493 071

25. Omuemu VO, Adamu SA. Assessment of breastfeeding knowledge and practices among working mothers in the federal capital territory Nigeria. Int $J$ Community Med Public Health 2019;6:20-9

26. Osibogun OO, Olufunlayo TF, Oyibo SO.

Knowledge, attitude and support for exclusive breastfeeding among bankers in Mainland Local Government in Lagos State, Nigeria.Int Breastfeed J 2018; 13:38 https://doi.org/10.1186/s13006-018-0182-9

27. Fosu-Brefo R, Arthur E. Effect of timely initiation of breastfeeding on child health in Ghana. Health Econ Rev. 2015;5:8

28. Oche MO, Umar AS, Ahmed H. Knowledge and practice of exclusive breastfeeding in Kware, Nigeria. Afr Health Sci 2011; 11(3): 518-523.

29. Ghimire U. The effect of maternal health service utilization in early initiation of breastfeeding among Nepalese mothers. Int Breastfeed J 2019; 14:33 https://doi.org/10.1186/s13006-019-0228-7

30. Zhang Y, Jin Y, Vereijken C, Stahl B, Jiang $\mathrm{H}$. Breastfeeding experience, challenges and service demands among Chinese mothers: A qualitative study in two cities. Appetite 2018; 128: 263-270

31. Rollins N, Bhandari N, Hajeebhoy N, Horton S, Lutter CK, Martines JC, et al. Why invest, and what it will take to improve breastfeeding practices? Lancet 2016; 387: 491-504

32. Mbada CE, Olowokere AE, Faronbi JO,Faremi FA, Oginni MO, OyinlolaAromolaran FC,et al. Breastfeeding profile and practice of Nigerian mothers: a crosssectional survey. Int $J$ Reprod Contracept Obstet Gynecol.2014;3(6):969-976.

33. Ihudiebube-Splendor $\mathrm{CN}$, Okafor $\mathrm{CB}$, Anarado AN, Jisieike-Onuigbo NN, Chinweuba AU, Nwaneri AC, et al. Exclusive breastfeeding knowledge, intention to practice and predictors among primiparous women in Enugu South-East, Nigeria. J Pregnancy 2019; 2019: 9832075. https://doi.org/10.1155/2019/9832075
34. Ogbo FA, Page A, Agho KE, Claudio F. Determinants of trends in breast-feeding indicators in Nigeria, 1999-2013. Public Health Nutr. 2015:1- 13.

35. Agho KE, Dibley MJ, Odiase JI, Ogbonmwan SM. Determinants of exclusive breastfeeding in Nigeria. BMC Pregnancy Childbirth 2011; 11:2. doi:10.1186/14712393-11-2.

36. Neifert MR. Breastmilk transfer: positioning, latch-on, and screening for problems in milk transfer. Clin Obstet Gynecol. 2004;47(3):656-675

37. Odom EC, Li R, Scanlon KS, Perrine CG, Grummer-strawn L. Reasons for earlier than desired cessation of breastfeeding. Pediatrics 2013; 131(3): e726-e732. doi: 10.1542/peds.2012-1295. 